\title{
SEXUALITY AND THE NATION: URBAN POPULAR MUSIC AND QUEER IDENTITIES IN KRÁMPACK
}

\author{
Elena Boschi \\ Liverpool Hope University
}

Since popular music entered film music studies debates between the mid-1990s and early-2000s (Romney and Wootton, 1995; Smith, 1998; Kassabian, 2001; Wojcik and Knight, 2001; Inglis, 2003; Lanin and Caley, 2005), scholarly attention for Spanish film music has grown (Vernon and Eisen, 2006; Fraile Prieto, 2010; Viñuela Suárez and Fraile Prieto, 2010) and contributions about songs quickly started appearing (Evans, 2002; Vernon, 2005; Shaw and Stone, 2012). There are obvious signs of a growing field including a broad range of disciplines. While different backgrounds produce a diverse picture, different disciplines can bring a certain focus, which predictably imposes a few recurrent limitations. Film scholars often focus on auteurs, often leaving not-yet-established directors off the scholarly map, while musicologists are still drawn towards the great film music composers - two sides that often come together to produce studies about established director-composer pairs. In Spain, film music studies remains largely centred in the musicological circles where these debates began and the interdisciplinary perspective which characterises Anglophone scholarship about Spanish films and their soundtracks has not yet reached film studies in the Spanish context.

Despite these limitations, all these contributions are shaping Spanish film music studies and pushing its growing scholarly community towards interesting and stimulating paths. However, there are interdisciplinary areas which I believe Spanish musicologists and film scholars could explore alongside one another. The present special issue has started exploring the first among these areas: the still under-studied compilation soundtracks. A focus often present in discussions about Spanish soundtracks is national identity, which, I argue, might inhibit exploration of a second area in need of research: audiovisual representations of other identities, especially those newly 'visible' identities whose visibility the soundtrack can often complicate. Obviously their consideration can add a new dimension to debates about national identity, but not replace these debates. Moving beyond national identity, a third area emerges which calls for further exploration: film music, gender, and sexuality. Considering how soundtracks construct gender and sexuality, I argue, can unearth other related divisions and add a further dimension to issues of national identity in film. Writing about gender and sexuality during 
Francoism, Barry Jordan and Rikky Morgan-Tamosunas discuss the 'highly traditional and retrograde concepts of gender and sexuality [which] led to the conflation of sexual and political repression in the cultural life of the dictatorship. [...] Issues of gender and sexuality thus became inextricably linked and highly politicised.' (1998: 112-3). Similarly, Steven Marsh and Parvati Nair note that gender theory can offer a fresh perspective on national cinemas, observing how

given the social and cultural relevance of gender, both during the dictatorship and in the more recent period of democracy, the construction of gender in Spanish cinema has been charged with ideological intent aimed at specific imaginations of national identities. [...] While Spanish cinema is incontrovertibly distinctive, the transnational borrowings of cinema as a fluid art form have produced important interventions in terms of how gender, and in turn nation, is imagined.

(Marsh and Nair, 2004: 4)

While the links between nation, Spain's political context, gender and sexuality are clearly being addressed, few authors explore their audiovisual dimension ${ }^{1}$ and fewer still discuss how transnational musical borrowings influence these representations. ${ }^{2}$ In this article I propose an audiovisual reading of Krámpack (Nico and Dani, Cesc Gay, 1998) which considers how popular music places gender and sexuality vis-à-vis the Spanish and Catalan nations.

Cesc Gay's adaptation of Jordi Sánchez's play (1998) is a tale of two teenagers home alone in the summer of sexual awakening. The story takes place in the Catalan seaside village where Dani's (Fernando Ramallo) parents own a house with swimming pool, sea views, and a French maid paid to look after him and his guest Nico (Jordi Vilches), who arrives right after Dani's parents leave for Egypt. Despite being bi-curios, Nico clearly likes girls and pursues Elena (Marieta Orozco) for the whole holiday, while Dani remains largely indifferent to Elena's cousin, Berta (Esther Nubiola). Dani's crush on Nico develops into intimacy. After one-off attempted penetrative sex, disappointment follows awkwardness and Dani seeks out Julián (Chisco Amado), a forty-something family friend Dani briefly falls for, who, however, quickly loses his charm. The two teenagers reconcile and Nico departs, leaving Dani alone again. In the closing scene Dani is shown sitting on the beach between two young women and a young man, considering the two options, and finally walking towards the sea. Finally, their bond seems unaltered despite the resentful reactions their sex experiments had initially triggered, but music marks Dani and Nico apart, and articulates other differences in the film: between queer and non-queer men; between different generations; and between the young women who disrupt homosociality and the young queer character.

The two adult women in the film have limited interaction with music. After Nico's arrival, Nico and Dani go home where Marianne (Myriam Mézières) - their maid - is sitting in the kitchen preparing gazpacho while listening to 'Ser Una Chica', a quiet acoustic song sung in Spanish by Myriam Mézières, the actor and screenwriter who plays Marianne. The other audible piece that could represent her is Bizet's 'Carmen', heard playing one evening while

1 Notable exceptions include Fouz-Hernández and Biddle (2012), Miranda-González (2010), and Poe Lang (2010).

2 Evans (2002) discusses Julio Medem's La Ardilla Roja (1993) drawing connections between English-language songs, imperialism, and threats against the patriarchal order. 
Marianne, Dani and Nico have dinner outdoors. Given Dani's and Nico's musical choices up to then, 'Carmen' could be assumed to be Marianne's choice or music Dani selects because Marianne is there. Marianne is French as is Bizet's 'Carmen', which makes the association between her and the piece quite obvious. Mézières's 'Ser Una Chica' is playing in the house while Marianne is there alone, which implies she chose the piece. These two different songs could represent Marianne's slippery identity - a beautiful Marseillaise who can speak perfect Spanish and prepare a Spanish specialty, often expresses dissatisfaction about her languishing social life, but talks encouragingly about leaving one's country to Nico after his impertinent enquiry about when she is returning to France. Interestingly, the multinational identity and placeless existence highlighted on Mézières's website ${ }^{3}$ biography closely matches the nationally ambiguous quality her character possesses, a feature partially constructed through the music surrounding her and potentially accentuated through any knowledge about Mézières's origins.

Despite being Spanish and without music Sonia (Ana Gracia) - Dani's private English teacher - enables Dani's exploration of a foreign culture and non-normative sexuality. Sonia teaches Dani English, which, alongside a conversation between her and Dani where she confesses her own queer teenage romance, can construct her character as a potential enabler as well as source of open encouragement and adult authorisation for Dani's own exploration of a foreign Other and his non-normative sexuality. Fouz-Hernández notes how 'the "foreign" and feminine influence of the maid and the teacher contributes to the boys' critical reorientation toward the macho and conservative ways of Francoist Spain and their further integration into the more modern gender attitudes of Northern Europe.' (2007: 229). Despite the reorientation and integration Fouz-Hernández talks about, Dani and Nico are musically set apart and the one Spanish-language track accompanies Nico's performance of masculinity aimed at Elena.

The sequences in which young women come between Dani and Nico are accompanied by upbeat party tunes in English. Like Marianne's source pieces, these songs are often performed by female vocalists. At the beach party where Dani and Nico are meeting the girls after their dinner with Marianne, English-language songs - all rather upbeat and featuring female vocalists - are playing while Elena and Berta come between Dani and Nico unknowingly. Later, the two friends throw a party at the house and welcome the two girls as 'Thank You' by Spanish garage rockers Doctor Explosion is playing on the stereo. 'Thank You' is sung by male vocalist Jorge Muñoz, but the band's style positions the piece alongside the other buoyant party tunes, setting these and Dani's quieter and often melancholic songs apart. At the house party, Nico improvises a strip tease to another Doctor Explosion piece, 'La Chatunga'. Interestingly, the one track performed by a Spanish band in Spanish accompanies the one non-queer boy doing a strip tease for the two Spanish girls. Berta is shown performing a shorter strip tease afterwards, but Nico dominates the scene and Dani, sitting between the two girls, watches and catches his clothes. Among the few non-English-language songs, 'La Chatunga' is perhaps the most prominent track, a source song that loudly invades the soundtrack, leaving other source sounds largely drowned out. The association between the piece and the Nico seems to point towards a musical partition between queer and heteronormative

3 'Daughter of an Egyptian father and a pianist mother of Czech origin, Myriam Mézières was brought up in France in an orphanage. But she considers the world of stage and screen as her real country.' <http://www.myriammezieres.net/en.php3> [Accessed 10 March 2010]. 
masculinity. Moreover, Krámpack has different musical choices not only for Nico, but also for the two girls who come between him and Dani, as I outline above, and for Julián, as I shall discuss later.

The moments where Dani can sense Nico wandering off and evading his affection are often accompanied by English-language songs. Overall, these are quieter, and include a few introspective indie ballads and one melancholic acoustic piece - 'Montserrat' by CatalanAmerican singer-songwriter Paul Fuster, which I shall discuss in depth later. The remaining English-language songs are written and performed by Majorcan indie rockers Satellite ('Where My Friends Are Gone' and 'In 1998') and short-lived Barcelona-based indie group Holland Park ('End of Summer' and 'Psychedelic Harpsichord'). All five songs share similar genre characteristics and melancholic lyrical content, sometimes reflected in the music, and all are indie songs performed in English by Catalan and Balearic bands who enjoyed significant success in Spain in the late 1990s.

The Satellites' piece 'Where My Friends Are Gone' appears twice to frame Dani and Nico's time together at home. After Nico's arrival, Dani is playing 'Where My Friends Are Gone' on the turntable in the house. As they hastily prepare for a fishing daytrip at the harbour, Nico talks about his growing Adam's apple and its association with virility, observing how girls see a big Adam's apple as a signifier of 'other things', after which Dani stops the music and the two friends leave the house. On the road to the harbour they meet Elena, a friend of Dani's, who invites the boys to join her and her cousin Berta at the bar for a drink. 'End of Summer' by Holland Park is playing in the bar where Dani resentfully witnesses Nico's growing curiosity for the two cousins.

Later, the party the two friends throw at the house ends, leaving Nico unsatisfied after Dani's Valium-laced sangria makes Berta ill and the two girls leave early. After their disappointing departure, Dani convinces a drunken and aroused Nico to move on from mutual masturbation and attempt penetrative sex instead. Nico accepts, comes without penetrating Dani, but refuses switching roles by playing the clichéd headache card. The morning after, Dani surprises Nico serving a sumptuous breakfast in bed, which makes him visibly uncomfortable. As they sunbathe poolside, 'Montserrat' by Paul Fustér is heard faintly playing in the house, when Dani suddenly asks Nico 'if I died, what would you do?' Nico looks quite perplexed and awkwardness between the two increases after Dani tells him 'I would not like to die by myself, I would like it if we died at the same time'. The volume increases, marking the music's shift from source to dramatic, and after a cut 'Montserrat' accompanies another scene where Dani fetches two beers and joins Nico outside. Dani expresses his affection for Nico again, and again Nico's awkward reactions leave him high and dry. The following scene unfolds indoors where Dani gives his brother's shirt to Nico as a present. Another melancholic piece, 'In 1998' by Satellites, is heard as awkwardness increases, but their botched attempt to cook macaroni in a dry frying pan temporarily lifts the tension.

Towards the end, another Holland Park track is heard as Dani, after finding out about Elena and Nico's planned sex encounter, tries to discourage Elena by proving Nico's homosexuality. 'Psychedelic Harpsichord' accompanies Dani's desperate attempt to prevent their encounter, which again exposes Dani's vulnerability about Nico. Right after Elena's departure, Dani rejects Berta's undesired courtship as 'Where My Friends Are Gone' is playing in the bar outside which Berta stops him. The Satellites' piece returns for the third and last time in the closing sequences where Dani and Nico reconcile, and are shown hunting in the hills and 
skinny-dipping off the rocky coast. The intro bridges the cut between the tracking long shot showing Nico and Dani sharing a joint and calling one another names after a brief, awkward appeasement and two short sequences showing their day on the hills and at the seaside. The music's initial dramatic placement changes as Nico is shown packing Dani's brother's shirt in the house where the piece has now audibly shifted to source. Their final moments together in the house combine awkwardness and irony. However, while the tension pervading the earlier sequences has obviously settled, the connotative meaning the piece has accrued through its earlier occurrences may suggest Dani's lingering emotional confusion.

Jazz music and a blues songs feature at Julián's house, where Dani joins him, Sonia, and their friends for a party the night Elena and Nico are meeting for pre-planned sex. After leaving Berta, Dani aimlessly rides his bicycle along empty residential streets and finds Julián unloading his car outside his house. Julián notices his bad emotional state and invites Dani, who initially refuses, but later returns and joins the party. Jazz music is playing in the dining room and a blues piece in English is heard shortly after in the kitchen where Julián and a guest are doing cocaine on the counter. Another blues piece follows later. While the songs Nico visibly engages and those accompanying every character whose behaviour threatens heteronormative masculinity and homosociality are set apart by the language of their lyrics, Julián's songs are set apart through their genre, drawing further divisions. All the young boys and girls are associated with contemporary songs, whereas the music surrounding Marianne and Julián is either inspired by or from earlier periods. Nothing resembling Marianne's acoustic song or opera is heard on the soundtrack and, while blues and jazz feature in the score, there is no other character defined through blues or jazz in the film world.

Julián's exclusive blues and jazz association may suggest different interpretations, which are worth investigating further. Blues is first heard on Julián's car stereo where a brief snippet of score turns to source during a chapter transition signposted by an intertitle. The cue stops after Julián is clearly seen turning off the music. The blues piece was originally composed for the soundtrack by Diaz, Prats, and Sabatés (authors of other shorter parts of chiefly bluesinfluenced score). The blues track, 'My Baby's Gone', appears in the end credits as 'licensed by Plusmusic', without authors or musicians named. Neither the anonymous Plusmusic piece nor the score parts are pre-existing songs. However, their clear genre aurally characterises Julián, placing his musical choices alongside Dani's non-Spanish-language songs, while setting the two men apart through the distinction between Dani's contemporary indie songs and the 'older' music which Julián's songs reference. Potential connections may arise between Julián's consumption of alcohol and cocaine and his music, however anonymous and stereotypical the blues and jazz he listens to might be. Furthermore, using jazz and blues for queer masculinity can suggest interesting interpretations for Julián's character. These musical choices can introduce ideas about black masculinity and discriminations against black men, revealing a complex portrayal for Dani's older crush. Blues and jazz's associative power and all the other information one gathers about Julián can combine and construct queer masculinity through connotations of authenticity ${ }^{4}$ that jazz and blues can bring. Alongside its potential connota-

4 'Authenticity' is a fraught concept in the field of popular music studies, where it 'is generally connected with how certain forms of popular music have typically been regarded as real or genuine while others have not. [...] Scholarship has largely avoided resting upon or reinforcing polarized notions of authentic and inauthentic popular music, regarding any claim to authenticity as primarily an ideological construction.' (Leonard and Strachan, 2003 : 164). Furthermore, 'authenticity' is a central concept for debates surrounding race and popular music. As Leonard 
tive baggage, the music surrounding him can evoke the discriminations African-Americans experienced and offer a correlation between the victims of racism and those of homophobia. Finally, while Dani's and Julián's songs reflect their different generations, revealing the differences between their own stories, all their songs share different but clear Anglo-American genre characteristics. The two men are routinely accompanied by these musically and lyrically 'foreign' songs, often performed by male singers. Both of Marianne's cues, on the other hand, are performed by female singers, as is the odd piece heard where Elena and Berta come between Dani and Nico.

Among the songs Dani chooses for the moments spent alone with Nico, Paul Fuster's 'Montserrat' calls for further consideration. After switching from source to dramatic in the lengthy sequence where Dani maladroitly expresses his emotional state, the piece appears again somewhere unpredictable and quite significant. At Julián's party Dani has several cocktails, pukes, and stays there for the night. The two spend the day after together, enjoy one another's company, and after returning to Julián's they kiss, hesitate, talk, kiss once more, and Dani seems serious about continuing, but stops and demands music. After his vague request for 'something that I like', Julián quickly picks something, but Dani doesn't approve, and Julián tries something different, which satisfies Dani. That song is Paul Fustér's 'Montserrat'. Julián exits briefly, leaving Dani alone for a few seconds, and returns to find Dani is gone. 'Montserrat', which briefly continues after the cut to Nico lying awake in Dani's bed, obviously reminds Dani of Nico, and the piece's evocative power makes him realise where his heart belongs. However, 'Montserrat', a melancholic Jeff Buckley-esque track, is a strange choice for Julián, since nowhere in the film does he play anything remotely like that song. Whether 'Montserrat' is playing on the radio or is among Julián's collection isn't clear. Still, Julián's involuntary or voluntary selection could taint his character's credibility to Dani's ears, precisely because a contemporary indie track could sound false in Julián's hands - perhaps an attempt to play down the generation gap between him and Dani two, projecting competence in the areas of popular culture he likes. Similarly, Dani earlier tells Julián he likes Western films and namedrops Ingmar Bergman, leaving Julián a bit surprised and perhaps unconvinced. However understated, their efforts to impress, perhaps to woo the other using his musical and cinematic taste, might suggest the impossibility for romance between their different generations.

Therefore 'Montserrat' comes as a memento not only of Nico, but also of Dani's own needs as a gay teenager who wants to go after a dream despite knowing he might never reach it. The piece's quiet melancholic melodic lines and lyrical content already foreshadow frustration for Dani's hopes about Nico, but Dani makes their being friends suffice until the end. The ambiguous final scene may suggest Dani's light-hearted outlook towards other romance opportunities surrounding him, but his walking towards the sea could suggest a direr end - maybe a final off-screen suicide - without the end credits music. Another upbeat blues piece specially composed for the soundtrack bridges the fade between the final shots showing Dani walking towards the water and the credits, which makes hearing a final off-screen suicide difficult and can instead suggest a new beginning - perhaps one involving reconsider-

and Strachan explain, '[v]arious African American musics [...] have been read as musical forms in which common practises [sic] such as signifyin(g) and antiphony are seen as following a direct line from African oral traditions' (2003: 165). While these ideas carried in the film world by jazz and blues are clearly constructed and therefore debatable, assumptions about its 'authenticity' nonetheless haunt films featuring jazz, blues, and any other music genre bearing connections to African 'roots'.

Quaderns, 9 (2014), pp. 87-95 
ing his sexuality. A third appearance of 'Montserrat' in lieu of this blues piece, for example, would upset the otherwise hopeful closing scene. Whichever end one reads using the audiovisual materials available, the meaning 'Montserrat' accrues through its two occurrences gives the piece a strange and complex connotation, which makes its evocative power trigger Dani's resolution to embrace an empty simulacrum, putting friendship where he hoped romance would bloom instead of abandoning it altogether. The differences between the songs heard in Krámpack develop complex differences between one character and another, marking apart generations, genders, and positions vis-à-vis heteronormative masculinity and homosociality and, perhaps obliquely, national identity. The connections between the textual threads I outline above are articulated through songs in Krámpack, where queer characters and liberal heterosexuals happily coexist without the clashes other films highlight. ${ }^{5}$ Krámpack minimises conflicts because its protagonist never finds himself confronting overt hostility. Dani's parents are not there, every adult character enables his new experiences, and the other teenagers never tease him for his sexuality. Nico never chastises Dani and their playful experiments never trigger violent rejection despite Nico's heterosexuality. Julián never pressures Dani. Everybody behaves faultlessly. While Nico's disinterest disappoints him, Dani expresses his sexuality without a problem and never represses any impulse - so much so that he even interrupts Elena and Nico's intimacy by grabbing Nico's crotch as he kisses Elena at the house party.

This total absence of hostile behaviour is matched by another glaring absence: Spanish bands singing songs in Spanish. The association between the one Spanish-language piece and the one heterosexual - if bi-curious - boy calls for further consideration. Krámpack's Catalan setting never emerges through traditional Catalan symbols, but there are a few Catalan and Balearic bands featuring on the soundtrack, whose songs, quite interestingly, accompany Dani's tormented emotional adventure. All these bands, however, write songs in English. One would not necessarily see Anglophone indie bands as being an overt expression of 'Catalanness'. Singing in English could be crudely equated to accepting Anglo-American's popular music's hegemonic influence. However, I argue, writing songs in English could acquire a different connotation. While singing in Catalan would place their music in the traditionally resistant Catalan nationalistic mould, writing songs in Spanish would label their music as acquiescing to Spain's nationalising power. Paul Fustér overtly addresses the issue in a brief quote that features on the Catalan website www.clubcantautor.com. US born Fustér talks about the six years spent in the parents' homeland as 'Un temps suficient per formar-se un criteri contrari al "nacionalisme i l'hermetisme" del rock català: "Continuo sense entendre per què hi ha senyeres als concert"' (Fustér, quoted in Tarrés). ${ }^{6}$ Their English-language songs can perhaps place these Catalan and Balearic indie bands somewhere 'neutral', since musically and lyrically the songs are neither for nor against any nationalist stances (Catalan and Spanish), and can place Dani's sexuality somewhere similarly non-aligned. Dani and his sympathetic friends inhabit a strangely 'neutral' seaside Catalonia where nothing seems stereotypically Catalan and yet the way the songs don't match potential expectations about their Catalanness, musically and lyrically, can produce identifications which are 'above' either nation, somewhere different where a certain knowing cosmopolitanism negates Catalan nationalism and Spain's

5 See, for example, Historias del Kronen (Montxo Armendáriz, 1995)

6 Enough time to form an opinion contrary to the "nationalism and the hermetism" of Catalan rock: "I still don't understand why there are flags at the concerts" (my translation)

<http://www.clubcantautor.com/artistes/fuster/index.htm> [Accessed 17 March 2010]. 
implied dominance. These 'foreign' songs accompany every character who rejects traditional ideas about heteronormativity and uncomplicated national identity, providing a culture their diverse group can share and fluid identifications for all those men and women who, for whichever reasons, are not finding their place where similar monolithic identities prevail.

Overall, popular music defines alternative textual paths along which audiences can negotiate their positioning vis-à-vis not only the surface identities the film overtly represents, but also those that are implied below the surface but nonetheless available. Krámpack's songs reflect different generations, genders, and stances vis-à-vis heteronormative masculinity through their genre, the performer's gender, and the different languages the singers use. Alongside the visuals, the songs construct positions ranging between subdued hostility against and general tolerance for queerness. These surface positions, I argue, can offer paths for identifications along which diverse sexualities and the Spanish and Catalan nations intersect. While the English-language songs which accompany every queer character can suggest their marginalisation vis-à-vis the Spanish nation, the Catalan and Balearic bands singing these songs in English might offer a means for expressing these identities' disengagement about the Catalan nation, leaving Dani and Julián without a place, musically relegated above these dichotomies. Considering how different sexualities are audiovisually represented, as I tried to illustrate, opens a new perspective for understanding not only how music articulates sexuality, but also how these representations and national identity interact.

\section{BIBLIOGRAPHY}

EVANS, Jo. "La ardilla roja: The Compulsive Nostalgia of Popular Love Songs", in Shelley Godsland and Anne M. White (eds), Cultura Popular: Studies in Spanish and Latin American Culture, Bern, Peter Lang, 2002, pp. 147-162.

FRAILE-PRIETO, Teresa. Música de cine en España: Señas de identidad en la banda sonora contemporánea, Badajoz, Diputación Provincial de Badajoz, 2010.

FOUZ-HERNÁNDEZ, Santiago. "Boys Will Be Men: Teen Masculinities in Recent Spanish Cinema", in Timothy Shary and Alexandra Seibel (eds), Youth Culture in Global Cinema, Austin, TX, University of Texas Press, 2007.

FOUZ-HERNÁNDEZ, Santiago and lan BIDDLE. "Voicing Gender: Performativity, Nostalgia and the National Imaginary in Spanish Cinema of the Democratic Era", in Lisa Shaw and Rob Stone (eds), Screening Songs in Hispanic and Lusophone Cinema, Manchester, Manchester University Press, 2012.

INGLIS, lan (ed.). Popular Music and Film, London, Wallflower, 2003.

JORDAN, Barry and Rikki MORGAN-TAMOSUNAS. Contemporary Spanish Cinema, Manchester, Manchester University Press, 1998.

KASSABIAN, Anahid. Hearing Film: Tracking Identifications in Contemporary Hollywood Film Music, New York, Routledge, 2001.

LANNIN, Steve and Matthew CALEY (eds). Pop Fiction: The Song in Cinema, Bristol, Intellect, 2005.

LEONARD, Marion and Robert STRACHAN. "Authenticity", in John Shepherd, David Horn, Dave Laing, Paul Oliver, and Peter Wicke (eds), Continuum Encyclopaedia of Popular Music of the World, Volume I: Media, Industry and Society, London and New York, Continuum, 2003, pp. 164-6. 
MARSH, Steven and Parvati NAIR. "Introduction", in Steven Marsh and Parvati Nair (eds), Gender and Spanish Cinema, Oxford, Berg, 2004.

ROMNEY, Jonathan and Adrian WOOTTON (eds). Celluloid Jukebox: Popular Music and the Movies Since the 50s, London, BFI, 2005.

SHAW, Lisa and Rob STONE (eds). Screening Songs in Hispanic and Lusophone Cinema, Manchester, Manchester UP, 2012.

SMITH, Jeff. The Sounds of Commerce: Marketing Popular Film Music, New York, Columbia UP, 1998.

VERNON, Kathleen M. "Las Canciones de Almodóvar", in Fran A. Zurián and Carmen Vázquez Varela (eds), Almodóvar: el cine como pasión: actas del Congreso Internacional "Pedro Almodóvar": Cuenca, 26 a 29 de noviembre de 2003, Cuenca, Ediciones de la Universidad de Castilla La Mancha, 2005, pp. 165-171

VERNON, Kathleen M. and Cliff Eisen. "Contemporary Spanish Film Music: Carlos Saura and Pedro Almodóvar", in Miguel Mera and David Burnand (eds), European Film Music, Aldershot, Ashgate, pp. 41-59.

VIÑUELA-SUÁREZ, Eduardo and Teresa FRAILE-PRIETO (guest eds). "Recent Approaches to Sound and Music in Spanish Audiovisual Media", special issue of Music, Sound, and the Moving Image, Liverpool, Liverpool UP, 2010.

WOJCIK, Pamela Robertson and Arthur KNIGHT (eds). Soundtrack Available: Essays on Film and Popular Music, Durham, NC, and London, Duke UP, 2001.

\section{Filmography}

ARMENDÁRIZ, Montxo, Historias del Kronen (Stories of the Kronen), 1995.

GAY, Cesc, Krámpack (Nico and Dani), 2000.

\section{Web Sources}

MEZIERES, Myriam [Internet] Available from:

<http://www.myriam-mezieres.net/en.php3>[Accessed 10 March 2010]

TARRÉS, Natxo, 'Paul Fuster - Paul Fuster, en el camí, amb Happy Nothing' on El Club de la Cançó Manresa, [Internet] Available from:

<http://www.clubcantautor.com/artistes/fuster/index.htm> [Accessed 17 March 2010] 
